Plant Tissue Cult. \& Biotech. 23(1): 31-38, 2013 (June)

$\overline{\text { PTC\&B }}$

\title{
Increase in Lipoxygenase Activity in Hairy Roots of Ambrosia maritima after Elicitation with Methyl Jasmonate
}

\section{Sameh AbouZid* and Yutaka Orihara}

Experimental Station for Medicinal Plant Studies, Graduate School of Pharmaceutical Sciences, The University of Tokyo, Hongo 7-3-1, Bunkyo-ku, 113-0033, Tokyo, Japan

Key words: Ambrosia maritima, Hairy roots, Polyacetylene, Lipoxygenase, Methyl jasmonate

\begin{abstract}
Hairy roots of Ambrosia maritima L. were cultured in MS in the dark. Time course production was studied for pentayneene and thiarubine A after addition of 40 $\mu \mathrm{M}$ methyl jasmonate to the 13-day-old hairy roots. The levels of pentayneene and thiarubrine A showed maximum increase after $72 \mathrm{hrs}$ adding methyl jasmonate. Lipoxygenase activity was increased in the hairy roots elicited with 40 $\mu \mathrm{M}$ methyl jasmonate. The increase in activity was 28 -fold higher than control cultures $24 \mathrm{hrs}$ after elicitor addition. The increase in enzyme activity was concomitant with the increase in pentayeneene, the precursor for polyacetylene biosynthesis. N-propyl gallate, a potent in vivo and in vitro lipoxygenase inhibitor, reduced polyacetylene production by the hairy roots at concentration of $100 \mu \mathrm{M}$. It is suggested that lipoxygenase may be at least partially involved in polyacetylene biosynthesis in A. maritima hairy roots.
\end{abstract}

\section{Introduction}

Lipoxygenases constitute a large family of nonheme iron-containing fatty acid dioxygenases that catalyze the regio- and stereo-specific dioxygenation of polyunsaturated fatty acids (Liavonchanka and Feussner 2006). The role of lipoxygenases in plant-microbe interaction is proposed to be mediated by lipid hydroperoxides and their derivatives (López et al. 2011). Jasmonic acid and its ester methyl jasmonate, secondary plant products derived from 13-hydroperoxide, are involved in the plant defense response through altering the gene

*Author for correspondence: <sameh.zaid@pharm.bsu.edu.eg>. Pharmacognosy Department, Faculty of Pharmacy, Beni-Suef University, Beni-Suef, Egypt. 
expression (Wasternack and Kombrink 2010). The mechanism by which jasmonate induces gene expression was studied in Catharanthus roseus (Van Der Fits and Memelink 2000). In this plant species, induction occurs through an ORCA3 transcription factor with a conserved jasmonate-response domain.

Ambrosia maritima L. (Asteraceae) is a common weed growing wild on the canal banks of the Nile in Egypt. The decoction of the aerial part of the plant is used for treatment of renal colic in the Egyptian folk medicine. This plant is also used as a molluscicidal agent for the control of the intermediate hosts of Schistosoma and faschiola (Singh et al. 2010). Present authors have previously reported the establishment and maintenance of hairy root culture from $A$. maritima (AbouZid and Orihara 2005). Hairy root cultures are obtained by genetic transformation of plant tissues with the pathogenic soil bacterium Agrobacterium rhizogenes. These roots have three main advantages: genetic and biochemical stability, cultivation without addition of growth regulators and ability to give high final biomass from low inocula. A. maritima hairy roots accumulated the polyacetylenes thiarubrine $\mathrm{A}$, thiarubrine $\mathrm{A}$ epoxide, thiarubrine $\mathrm{A}$ diol and pentayneene after elicitation with $40 \mu \mathrm{M}$ methyl jasmonate for $72 \mathrm{hrs}$ at day 13 of the culture period. These compounds showed toxicity against microorganisms (Hudson et al. 1989, Towers et al. 1993), insects (Guillet et al. 1997) and nematodes (Bakker et al. 1997). It was proposed that the biosynthesis of these polyacetylenes in A. maritima hairy roots proceeds via a catabolic pathway involving linoleic acid (AbouZid and Orihara 2007). In this study, time course production of pentayeneene and thiarubrine A (Fig. 1) was studied after addition of methyl jasmonate to A. maritima hairy roots. The increase of lipoxygenase activity after elicitation of $A$. maritima hairy roots with methyl jasmonate is reported. Inhibition of lipoxygenase by $n$-propyl gallate is discussed.

\section{Materials and Methods}

Enzyme activity was measured on a Pharmacia Ultrospec $3000 \mathrm{UV} /$ visible spectrophotometer. HPLC analysis was carried out with a Shimadzu liquid chromatograph equipped with 2 LC-10 AD pumps, SPD-M10AVP photo-diode array detector, de-gasser DGU-12A, Inertsil ODS-3 $5 \mu(4.6 \times 250 \mathrm{~mm})$ column for analytical purposes. Methyl jasmonate and $n$-propyl gallate were purchased from Sigma Chemicals. All procedures were done in dim light to prevent the photo-degradation of thiarubrines.

Hairy roots of $A$. maritima were established and T-DNA integration into the plant genome was confirmed as previously described (AbouZid and Orihara 2005). The hairy roots were maintained in hormone-free MS liquid medium (250 
$\mathrm{ml} / 500 \mathrm{ml}$ Erlenmeyer flask) in the dark on a rotary shaker at $50 \mathrm{rpm}$ and subcultured every 28 days.

A. maritima hairy roots were cultured on a rotary shaker at $50 \mathrm{rpm}$ in MS liquid medium in the dark. Elicitation was performed on 13-day-old root cultures by exposure to $40 \mu \mathrm{M}$ methyl jasmonate. The cultures at day 13 were in the log phase of growth. The elicitor filtered through $0.22 \mathrm{~m}$ syringe filter. Control cultures received distilled water. After $72 \mathrm{hrs}$ hairy roots were harvested for analysis of enzyme activity and polyacetylene content.

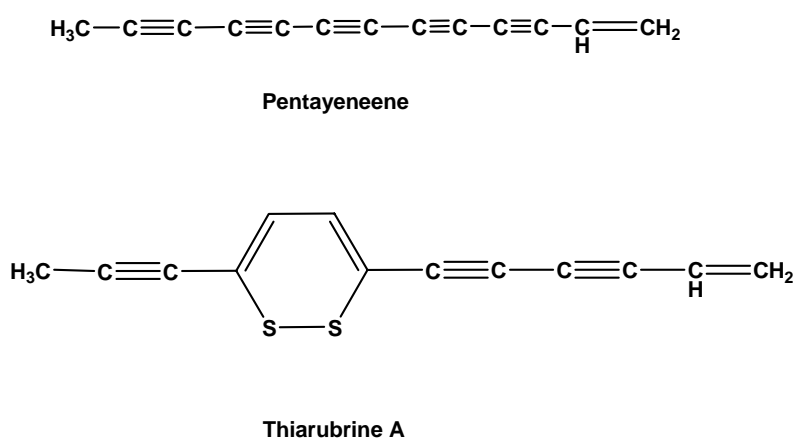

Fig. 1. Chemical structures of pentayeneene and thiarubrine A isolated from the hairy roots of Ambrosia maritima.

A. maritima hairy roots were harvested at different time points by vacuum filtration, freeze-dried then homogenized with excess $\mathrm{CHCl}_{3}$ in a mixer. The extract was evaporated to dryness and the residue was dissolved in methanol. The methanol solution was filtered using Advantec No. 2 filter papers, and then the volume was made to $5 \mathrm{ml}$. Analysis was made on HPLC. The temperature was maintained at $40^{\circ} \mathrm{C}$. The flow rate was $1 \mathrm{ml} / \mathrm{min}$. Iso-cratic elution with $\mathrm{H}_{2} \mathrm{O}$ : $\mathrm{MeOH}(20: 80)$ mixture afforded the following retention times for the different polyacetylenes: thiarubrine A diol $7.2 \mathrm{~min}$, thiarubrine A epoxide $17.7 \mathrm{~min}$, thiarubrine A $34.8 \mathrm{~min}$, pentayneene $42.9 \mathrm{~min}$. Polyacetylenes were quantified at $480 \mathrm{~nm}$ using standard curves derived from the isolated compounds.

A. maritima hairy roots were collected at different time points by vacuum filtration and homogenized over ice in $0.1 \mathrm{M}$ sodium phosphate buffer $\mathrm{pH} 7.2$ at a ratio of $3 \mathrm{ml}$ buffer: $1 \mathrm{~g}$ fresh weight roots and $30 \mathrm{mg}$ polyvinyl pyrrolidone. The homogenate was centrifuged at $12100 \mathrm{~g}$ for $20 \mathrm{~min}$ at $4^{\circ} \mathrm{C}$ and the supernatant was used. Linoleic acid (50 mg) was added to $2 \mathrm{ml}$ ethanol and mixed with $8 \mathrm{ml}$ borate buffer $(0.2 \mathrm{M}, \mathrm{pH}$ 9) by ultra-sonication. The solution was cleared by addition of $\mathrm{NaOH}$ (250, 1 M solution) and diluted to $25 \mathrm{ml}$ with the borate buffer. The assay mixture consisted of $50 \mu \mathrm{l}$ of enzyme extract, $0.95 \mathrm{ml}$ 
borate buffer and $5 \mu \mathrm{l}$ substrate solution. The assay was run for one minute at $25^{\circ} \mathrm{C}$ and monitored at $234 \mathrm{~nm}$ using UV spectrophotometer.

The protein content of the extracts was determined using Bradford reagent (Bradford 1976). A commercial preparation of soybean lipoxygenase (Sigma) was used as the standard protein (specific activity 5 units/mg protein).

$\mathrm{N}$-propyl gallate was added to dark-grown A. maritima hairy roots control and elicited cultures. The inhibitor concentration was adjusted to make a final concentrations of 50, 100 and $200 \mu \mathrm{M}$. Hairy roots were harvested and polyacetylene content was determined.

The results are expressed as mean \pm SE $(n=3)$. Statistical significance was determined by ANOVA with $\mathrm{p}<0.05$ considered significant.

\section{Results and Discussion}

A. maritima hairy roots were cultured in the dark at $25^{\circ} \mathrm{C}$ on a rotary shaker at $100 \mathrm{rpm}$. Three lines were characterized that showed different growth rates in hormone-free liquid MS (AbouZid and Orihara 2005). Forty $\mu \mathrm{M}$ methyl jasmonate, added to 13-day-old cultures for $72 \mathrm{hrs}$ ), enhanced polyacetylene production by the established hairy roots. Pentayneene and thiarubrine A levels were determined using HPLC at different time points $(12,48,72,120,168 \mathrm{hrs})$ after addition of methyl jasmonate. Results are shown in Fig. 2. The levels of pentayneene and thiarubrine A showed maximum increase $72 \mathrm{hrs}$ after addition of methyl jasmonate. At all the specified time points, there was an almost constant ratio between the levels of pentayneene and thiarburine A. The former compound, a precursor for thiarubrine A biosynthesis, was present in almost twice that of thiarubrine A.

Lipoxygenase activity was determined in hairy roots of A. maritima after addition of $40 \mu \mathrm{M}$ methyl jasmonate to the 13-day-old cultures. The hairy roots were at the middle of log phase of growth at this day. These conditions achieved maximum yield of polyacetylenes from the hairy roots.

Lipoxygenase activity was determined spectrophotometrically in hairy root homogenates using linoleic acid as a substrate. Linoleic and $\alpha$-linolenic acids are natural substrates of lipoxygenase in plants. A time course experiment showed a significant increase in lipoxygenase activity in hairy roots elicited with methyl jasmonate compared to control (Fig. 3). Low basal activity was observed in control. Lipoxygenase activity showed a peak $24 \mathrm{hrs}$ after addition of methyl jasmonate. 


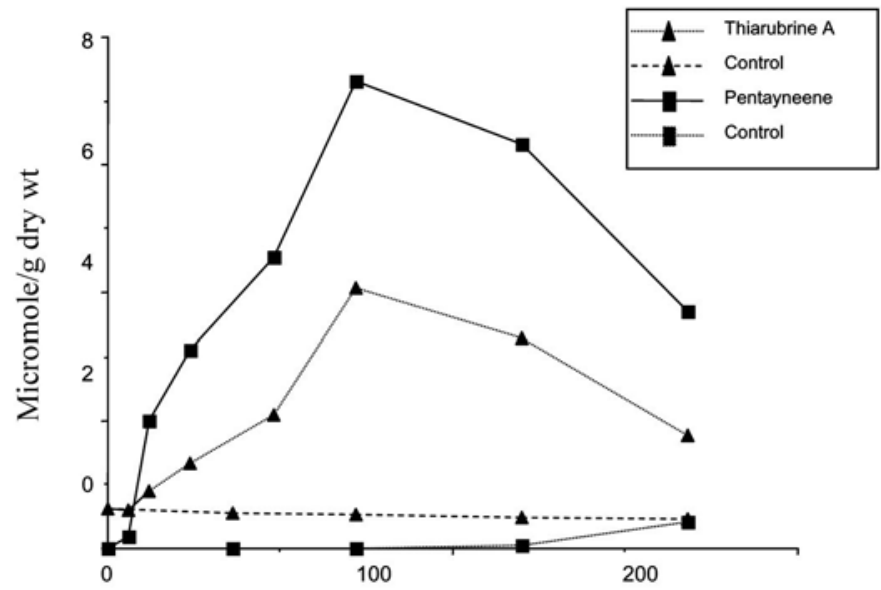

Time after adding methyl jasmonate (hrs)

Fig. 2. The enhancement of pentayneene and thiarubrine A content in hairy roots of Ambrosia maritima after addition of methyl jasmonate.

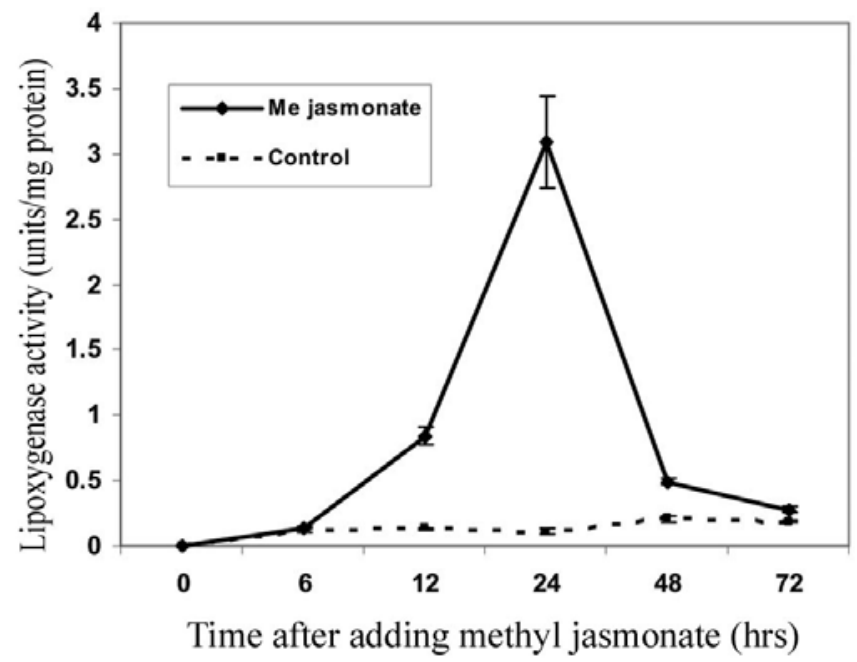

Fig. 3. Change in lipoxygenase activity after addition of methyl jasmonate to Ambrosia maritima hairy roots cultured in the dark.

The effect of lipoxygenase enzyme inhibition on polyacetylene production was investigated in A. maritima hairy roots. Lipoxygenase can be inhibited by trans-unsaturated fatty acids, acetylenic acids, $\alpha$-bromofattay acids, antioxidants and oxygen scavengers. $N$-propyl gallate as an oxygen scavenger has been previously shown to be an effective lipoxygenase inhibitor both in vitro (Siedow and Girvin 1980) and in vivo ( Fobel et al. 1987). Polyacetylene production was 
significantly reduced after $n$-propyl gallate was added to A. maritima hairy roots at $100 \mu \mathrm{M}$ (Fig. 4). It is to mention that polyacetylene production in Bidens sulphureus did not decrease when n-propyl gallate was used to inhibit lipoxygenase (McKinley et al. 1993).

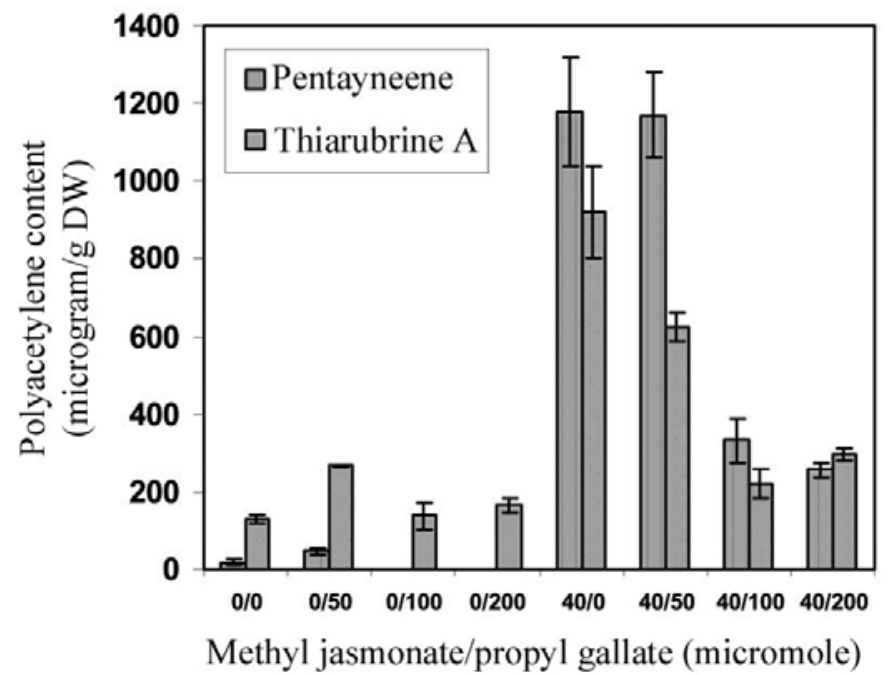

Fig. 4. Polyacetylene production after addition of $n$-propyl gallate to hairy roots of Ambrosia maritima elicited with methyl jasmonate.

Methyl jasmonate was shown to induce lipoxygenase in tobacco cells over a wide concentration range with a maximal response at $890 \mu \mathrm{M}$ (Veronesi et al. 1999). In Arabidopsis thaliana, lipoxygenase mRNA levels were induced upon treatment with methyl jasmonate (Melan et al. 1993). In tomato leaves, a gene encoding lipoxygenase was transiently induced by methyl jasmonate (Heitz et al. 1997). A methyl jasmonate-responsive region in the promoter of a lipoxygenase gene was identified in barely grain (Rouster et al. 1997). Lipoxygenase activity showed a transient increase in activity in hairy roots of Bidens sulphureus when the cultures were elicited with crude mycelial extract of Pythium aphanidermatum (McKinley et al. 1993). In the referred study, it was suggested that lipoxygenase is not involved in polyacetylene production in that plant species based on enzyme inhibition experiments. Contradictory to these results, the yield of polyacetylene-like products of lipoxygenase activity in Centaurea ruthenica callus cultures has led to the suggestion that lipoxygenase is involved in polyacetylene biosynthesis (Jente et al. 1988).

In conclusion, it is postulated that polyacetylenes may be produced from linoleic acid in a pathway that is affected by lipoxygenase or one of its products in a similar fashion as other lipoxygenase products involved in plant defense are 
produced. This does not exclude the possibility that the methyl jasmonate induced lipoxygenase generates internal jasmonate by action on linolenic acid. This endogenous jasmonate may be responsible for the production of polyacetylenes in hairy roots of $A$. maritima.

\section{References}

AbouZid S and Orihara Y (2005) Polyacetylenes accumulation in Ambrosia maritima hairy root and cell culture after elicitation with methyl jasmonate. Plant Cell Tiss. Org. Cult. 81: 65-76.

AbouZid S and Orihara Y (2007) Biosynthesis of polyacetylenes in Ambrosia maritima hairy root culture. Planta Med. 12: 1327-1329.

Bakker J, Gommers, FJ, Nieuwenhuis I and Wunberg H (1979) Photoactivation of the nematicidal compound a-terthienyl from roots of marigolds (Tagetes species). J. Biol. Chem. 254: 1841-1847.

Bradford MM (1976) A rapid and sensitive method for the quantitation of microgram quantities of protein utilizing the principle of protein-dye binding. Anal. Biochem. 72: 248-254.

Fobel M, Lynch D and Thompson JE (1987) Membrane deterioration in senescing carnation flowers: coordinated effects of phospholipid degradation and the action of membranous lipoxygenase. Plant Physiol. 85: 204-211.

Guillet G, Philogene GJR, O’Meara J, Durst T and Arnason JT (1997) Multiple modes of insecticidal action of three classes of polyacetylene derivatives from Rudbeckia hirta. Phytochemistry 46: 495-498.

Heitz T, Bergey DR and Ryan CA (1997) A gene encoding a chloroplast-targeted lipoxygenase in tomato leaves is transiently induced by wounding, systemin, and methyl jasmonate. Plant Physiol. 114: 1085-1093.

Hudson JB, Graham EA, Miki N, Towers GHN, Hudson LL, Rossi R, Carpita A, and Neri D (1989) Photoactive antiviral and cytotoxic activities of synthetic thiophenes and their acetylenic derivatives. Chemosphere 19: 1329-1343.

Jente R, Richter E, Bosold F and Olatunji GA (1988) Experiments on biosynthesis and metabolism of acetylenes and thiophenes. In: Chemistry and biology of naturally occurring acetylenes and related compounds, Lam J, Breteler H, Arnason T (eds.), Elsevier, Amsterdam. pp. 187-199.

Liavonchanka A and Feussner I (2006) Lipoxygenases: occurrence, functions and catalysis. J. Plant Physiol. 163: 348-357.

López MA, Vicente J, Kulasekaran S, Vellosillo T, Martínez M, Irigoyen ML, Cascón T, Bannenberg G, Hamberg $\mathbf{M}$ and Castresana C (2011) Antagonistic role of 9lipoxygenase-derived oxylipins and ethylene in the control of oxidative stress, lipid peroxidation and plant defence. The Plant J. 67: 447-458.

McKinley TC, Michaels PJ and Flores HE (1993) Is lipoxygenase involved in polyacetylene biosynthesis in Asteraceae? Plant Physiol. Biochem. 31: 835-843. 
Melan MA, Dong X, Endara ME, Davis KR, Ausubel FM and Peterman TK (1993) An Arabidopsis thaliana lipoxygenase gene can be induced by pathogens, abscisic acid and methyl jasmonate. Plant Physiol. 101: 441-450.

Rouster J, Leah R, Mundy J and Cameron-Mills V (1997) Identification of a methyl jasmonate-responsive region in the promoter of a lipoxygenase 1 gene expressed in barely grain. Plant J. 11: 513-523.

Siedow JN and Girvin ME (1980) Alternative respiratory pathway its role in seed respiration and its inhibition by propyl gallate. Plant Physiol. 65: 669-674.

Singh SK, Yadav RP and Singh A (2010) Molluscicides from some common medicinal plants of eastern Uttar Pradesh, India. J. Appl. Toxicol. 30: 1-7.

Towers GHN, Bruening RC, Balza F, Abramowski Z and Lopez-Bazzochi I (1993) Thiarubrine antifungal agents. U.S. Patent 5,202,348.

Van Der Fits L and Memelink J (2000) ORCA3, a jasmonate responsive transcriptional regulator of plant primary and secondary metabolism. Science 289: 295-297.

Veronesi C, Pouenat ML, Rickauer M and Esquerre-Tugaye MT (1999) Regulation of tobacco lipoxygenase by methyl jasmonate and fatty acids. Comptes Rendus de l'Académie des Sciences-Series III-Sciences de la Vie 322: 491-497.

Wasternack C and Kombrink E (2010) Jasmonates: structural requirements for lipidderived signals active in plant stress responses and development. ACS Chem. Biol. 5: 63-77. 